najor purpose of the I echnisrmation Center is to provide oadest dissemination possi$f$ information contained in Research and Development s to business, industry, the nic community, and federal, and Incal governments. hough a small portion of this is not reproducible, it is made available to expedite ailability of information on the ch discuss?d herein. 
TITL NATURAL CONVECT, ON HEAT TRANSFER BETWEDN AREAS OF HORIZONTAL CYLINDERS AND THEIR ENCLOSURE

aUTMOAIS, R. A. Weaver, C-10

x: . . . .

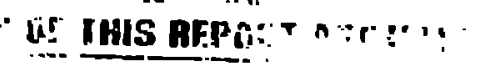

anen reproductirs:

Eund to permiti at: . i.... .. is inishbility.

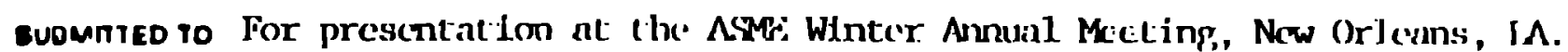
Decomber 10-14, 1.98\%.

\section{IBISC I.AIMIIR}

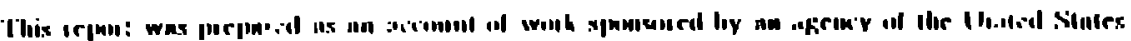

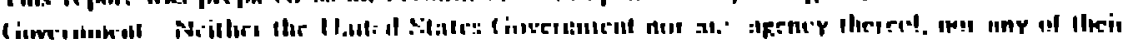

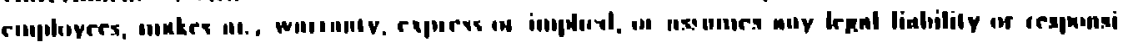

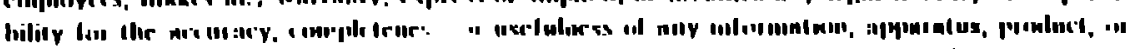

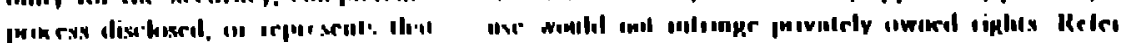

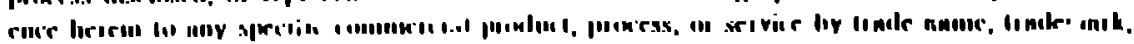

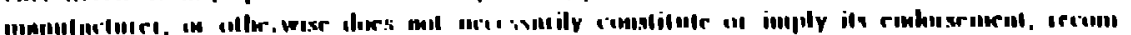

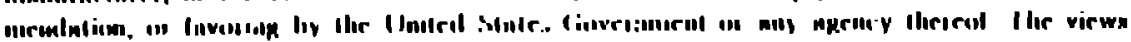

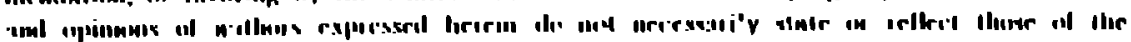

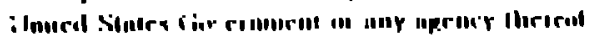




\title{
NATURAL CONVECTION HEAT TRANSFER BETWEEN ARRAYS OF HORIZONTAL CYLINDERS AND THER ENCLOSURE
}

\author{
R. A. Werver \\ Computing and Communications Dirision \\ Los Alamos National Laboratory \\ Loo Alamos, NM \\ h. O. Warringtoo \\ Mechanical Engineering Department \\ Louisiana-fESWUniversity \\ Rustou, LA
}

\begin{abstract}
The natural convection heat transfer between arrays of horizontal, heated cylinders and cheir iouthermal, cooled en-losure was experimentally investigated. Four different cylinder aprays were uned: two in-line and iwo alaggered. Four fuids (air, water, 20 cs silicone, and $06 \%$ slycerinc) were used with Prandll numbers ranging from 0.706 wo 13000.0 . There was no signiflcant ch: age in tho Nucselt number belween isothermal and constane beat finx conditions of the cyliader arrays. Tho averago heat trausfer coefilctent wan most affected by tho upaing between cylinders and the total surfaco area of the cylinder arrayn. The enclosure reduced the expectid increane It both the average and the losal heat transfi: corfmeionte caused by changing the inner boily from an in-line arrangeinent to a olakgred arrangement of comparable apncing. An encrease in finid vinc saity reduced the infuersec of the acomolric cffecto.
\end{abstract}

\section{POMENCI,ATURE}

A. Surface aren of the inner body

d. Surlace neea of the oucer body

1) I,ength of boundary layer on onn eylinder, $\|=\pi(: / / 2)$

c. Specifie lient at conatant prennere

d Dlameter of $a$ eylinder

R Acceleration of gravily. O.R1 $\mathrm{m} / \mathrm{nsc}^{\circ}$ b Heat transfer coefficieal,

$h=Q_{C O N} / A_{1} \Delta T$

l Thermal conductivity

L Hypot'sctical gap widtb, $R_{0}-R_{\text {, }}$

$N_{X} \quad$ Nussclt number, $h X / k$, where $X$ is any characteristic length

Pr Prandul number, $c, \mu / k$

Qconv Heat transfer by convection

Max Rayleigh number, ${ }^{A} \rho^{2} p\left(T_{1}-T_{0}\right) X^{3} c_{p} / \mu k$, where $X$ is any characteristic lengulı

$R a_{X}^{*} \quad$ Modifed Rayleigh number. $\left.R a_{x}=R a_{X i}=/ R_{,}\right)$

$n$ Radius of a hypothetica! sphere equal in volume to the yolume of one eylinder tiunen the number of cylindern in the cylinder array

fi. IRadius of a hypothetical ophere equal in volume to the outer hody

5 Characteristic Irngth, $S m\left(\pi, \quad R_{1}\right)\left(-1, / A_{0}\right)$

T. Inner body emperature

T. Outer body temiperature

$\Delta \Psi \quad$ Temperalure dillerence, $\Delta T, . T$, $T$,

$X \quad$ Auy charneteristic lenxth

A Thermal expansion coeffletent

a Dyonamie Yisconil.y

$n \quad$ Rutic, of eircte circumferener en it:! liamres: (3.14150)

p Dennity of the nuid 


\section{INTIRODUCTION}

Nalural convection heat transfer from a body $h$ an inflaile Quid medium bas received extensive experimental and analytical study in the past, while relatively little attention has been devoted to naiural conrection withio an enclosure. The increace in complexity. caused ty the strons interaction between loe brundary layer and the adjacent tuid, bas made it difflcult to obtain a solution to the problem of natural convection in an enclosure. However, inlerest in this area is dramatically incrcasing because of the important applications it has in areas such as nucleap reaccor lecboology, electronic instrumentatior packaging, airctall cabio design, crucle oil ulorage cank degiga, solar collector design, and energy storage syslems.

One of the tist in-depth experimental studies of aaturaj coavection in enclosures was performed by Warrington [1]. The heat transfer from inner bodies such 23 spheres, cubes, and cylinders to both epherical and cubical enclosures was investigated.

Larson, Garcliog, and Schimmel [2] used laser incerferometry to experiruentally cetermine the cemperature feld around a iealed, horizuntal cylioder in an isothermal, rectanguiar cnclosure.

Dutton and Welty [3] conduciet an expcrimental study of aatural convection lest transfer in an array of uniformly tealed vertical cylindero ourrounoed by a vertical, cyliadrical encisouro with mercury as the fluid nedium. Theis reoules indicated that the natural convection beat transfer wao fitrogly dependent on the cylinder epacing

Van De Sande and Ilamer |1| atudied the steady and tenusient natural convection heat tranofer between horizontal, concentric cyliodero with conalant heat tux surface conditions. Their experiment showed that n sidewise displarement of the inner cylinder did not affect the hea: trannfur resulto. llowever, the overall heat transfer decreaned or increaued depending on whether the inner cylinder was above or helow the centerline of the weter cyllnder.

Crupper (b) performed an experimental nludy of natural conrection hea: tranafer between a not of tour laothermal, heatird eyllndern nnd an inotlirrinnl, cooled, culicical racinaure to determino the eflect of the ponitioning of the cylindern within the enclonure.
Powe $|6|$ investigated the limits of relatire gap width for which available correlation equations for usiural convection beal transfer in enclosures were applicable. Heat transfer rates for large relative sap widtbs were shown to be limited by those obtained for free convection to in infoite fuid medium, and this criterin was used to calculate a maximum relative gap width for wich t'ie enclosure equations were applicable. A minimum realtive 8 ap width for applicabiaity of the enclosure cquations was determined by the pure conduction limit.

Brown |7| experimentally studied the eficcts of reduced pressure on the aatural convection from a cylinder and a cube is a cubical enclosure.

Powe, Warringlon, sad Seaulan [8] rerformed a detailed study of Batural convection Dow phenomena that occur betwaen a bodj of relatively arbitrary shape and its spherical enclosure. Resulting trends in the fuid fow daia were established io facilitate betler predictions of the heat transfer in problems of natural convectiou in enclosures.

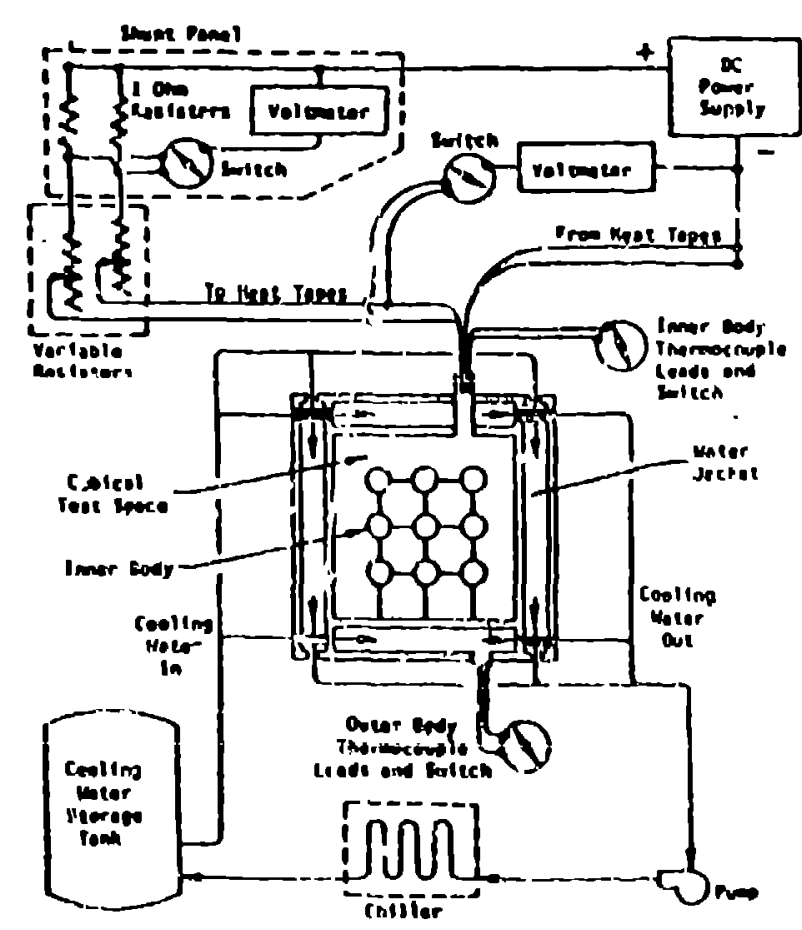

Figure 1. Sichenatic of the beat tramifer npparat-in 

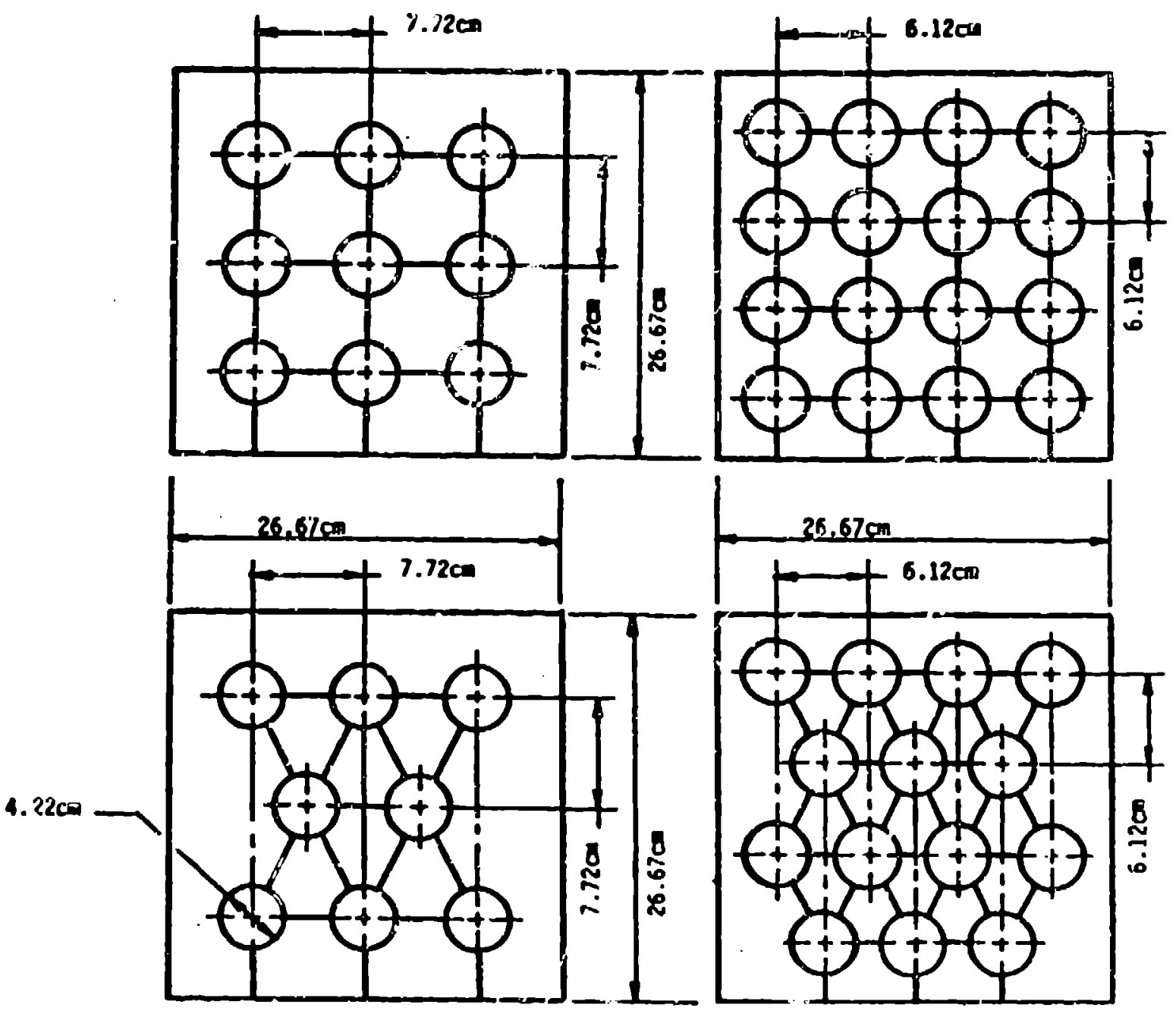

Figure 2. The four cylinder arrangements

The purpose of this study is to experimeneslly inreatigate the digsipation of heal by untural convection from arruys of beaced, hririzontal cylinders to a rooled, isothermal, culbir al enclosure. The cylinders are subjected 6 , boilh isothermal and conotant bent fur conditiono. Four \#uida and fous cyliader confgurationa are utilized. The Auids used aro air, water, $06 \%$ slycerine, and 20 co sillicone. The four cylinder ccinfgurntions connist of two in-line arrangemento using aine and oixlcen cylinriers and two htophered arrangenento using cighe and fourtecn cylindern.

\section{APPARATUS AND PROCEDURE}

Tben enclosure uned for thin inventifacion was a cube $20.07 \mathrm{~cm}$ along an inser nide, conotructed fromII 1.27-cen-thick, lype 0001, nluminum. ^ water jacket enclogure, which measured $38.1 \mathrm{~cm}$ on a eide, surrounded the cubical tege space. The waler jacket consisted of ai irparale rertangular channels rach $3.175 \mathrm{~cm}$ in widit, which gave une chnnecl for each fa e of the tegl apiere. The llow of cooling water to cach of the camecels was fred by 4 manifold njaterr. ard adjented (1) maincain the cube that enclooed ihe lese npare at isothi:rmal conditions. The conllng waler was collected from the water jarket and puinped throulgh a chiller into n otorage tank rad then back in to the water jacket. A nchomialic of the npplaralun is alown in Figure 1

The four different arrangementa of horiznntal hented cyllndern that wete uned for inner geonetrics are nhuwn in Figure 2. The cylinders were conbtructed from 0.30-rm-thick romper pipe 
$10.16 \mathrm{~cm}$ long, and $4.22 \mathrm{~cm}$ ontside diameter. Copper end caps $0.25 \mathrm{~cm}$ thick and $1.22 \mathrm{~cm}$ is diameler were mounted to both eads of each cylinder. The support structure for each array of cylindere conaisced of wooden dowels $0.32 \mathrm{~cm}$ in diameter.

Heat was supplied to th. inside surface of each cyinder with electrical resiatance beal tape and a direct current powes source. Input voltages to the heat tapes were controlled individually with variable power resistors that were connected in series with the heat tapes. The inside surface temperatures of the coclosing cube and the outside surface temperatures of the cylinders were suonitored with embedded copper-constantas chermocouples.

Sixlecd huid/geometry combinations were used to obtsin 172 data points, consisting of both isothermal and constant beat bux conditions for the inner geometries. Afler centering one of the in ner geometrics in the enclosure and fling the enelosure with one of the luids, power was applied to the cylinders and cooling water was pumped through the water jacket. When equilibrium was established (2pproximately $2-1$ hours) and the power was iaput to each eylinder, then the cylinder temperatures and the enclosure temperatures were recorded.

The heat transferred hy datural convection was obtained by subtracting the heat transferref by radiation and conduction from the total amount of beat transferred. The conduction lo:s through the support structure, through the th:- mocouple lead wires, and through the heat tape lead wires was obtained with a one-dimensional analysis. Because the waler, 20 cs silicone, and $90 \%$ glycerine were opaque to radiation, only the data using air as tha tuid aceded a correction foradiation. The radiation loss was experimentally obtained by evacuating the legt space betwcen the cylinders and the enclosure $w a$ a pressure below so $\mathrm{\mu m}$ and subtracting the conduction losses from tóe total power iaput.

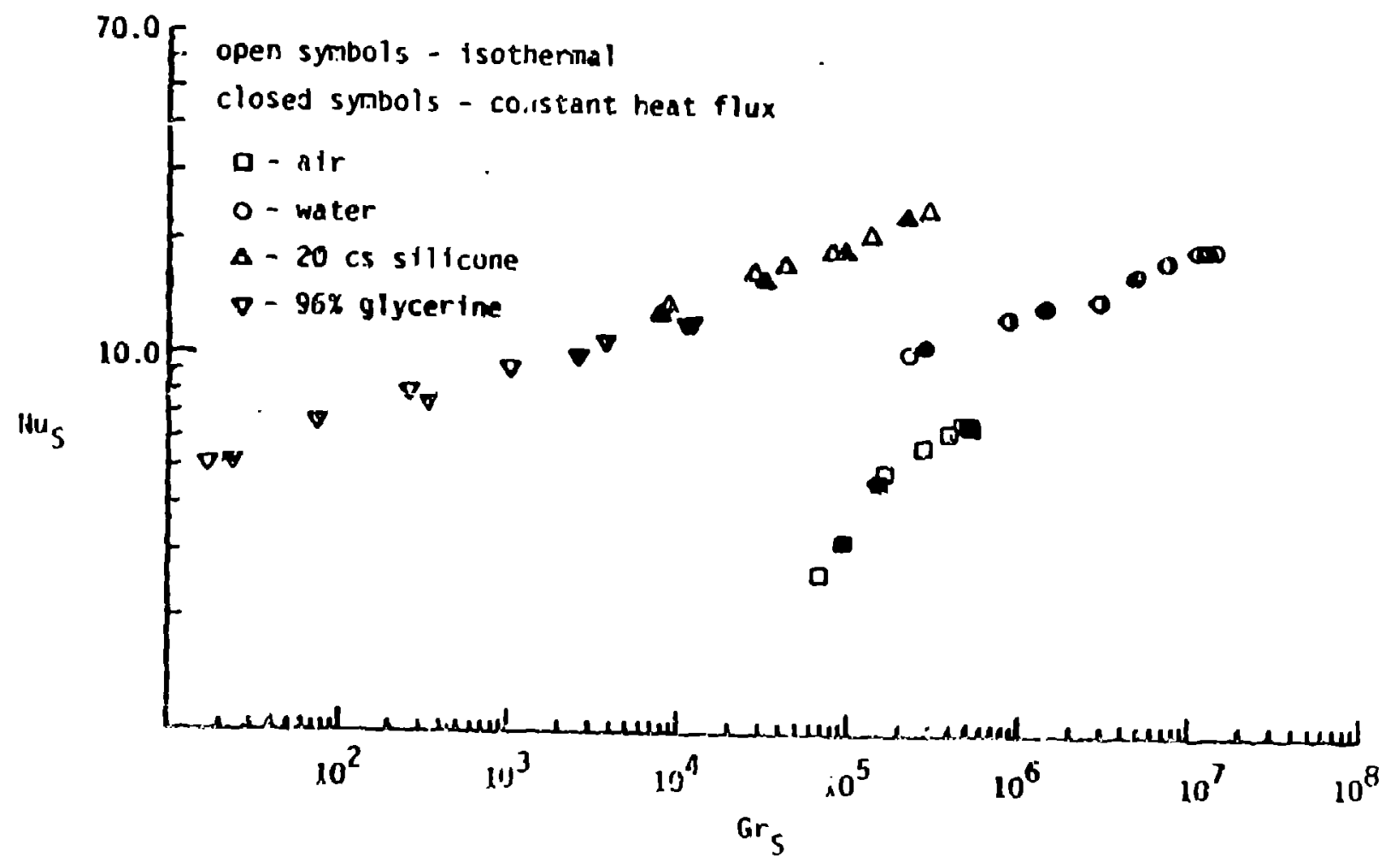

Fipure 3. Comparion of the hent eranofes for isothermal and conotant lieat nux inuer loody conditionu uning dats from the right.-rylinder arrangrment 


\section{RE8UนT8}

The Rayleigh aumber. Nuarell number, Prandel nomber, and atio of characteristic lengths were used in scveral combinztions to correlate the experimental data. When calculat ins the Rayleigh and Nusselt numbers for use in the correlation equations, it was found that three different characteristic lengths consiztently yielded the beat results. The Bap width, L, was defoed 10 be the distance between hypothetical er centric opheres of volumes equal to the actual ve ines of the eaclosure and the cylinder arrays. $A$ was defined to be the radius of a sphere that was equal in volume o that of the cylinder array. B was the approximate distance traveled by the boundary layer on one horizontal cylinder (assuming no low separation). This distance was deflned to be one-balf of the outer circumference of a cylinder.

A compaison of isothermal to constant heat Aux condit: ans for one cylinder arrangement is sl.cw in $\Gamma_{1}:$ :.e 3. For any one of the four iluids, the average i Jusselt number of the constant heat fux dato coincided very closely to the isotkermal data, was the case for the thrce remaining cylinder arrangements. The average Nusgelt number was derived usiag tbe total amount of heat tranoferred by natural convection from the cylinder array to the enclosure.

Althougb there was no oignifisant diffeseace in the average beat transfer coefficient for the entiro cylinder array, the local hall trungfer coefficat for the cylinder rows ohowed aoticeable difference wt.cn changing from isolbermal to constant beat conditions. When conotant heat flux conditions were imposed, the upder rowo of cylinders were lorced to increasingly higher temperntures than that of the bottom row of eylinders. Because the enclonure caused an increase in convective activity in the upper regions of the test space, the bigher temperaturo of the upper rows sugmenled the driving potential for tho heal transfer, resuleing in a higber local heat transfer cocfl.cicul for the upper rown.

The beat correlaticn for all of the isothermal dale. was

$$
N u_{b 1}=0.220 R a_{b}^{0.257}\left(I / / R_{1}\right)^{0.040} / 4^{0.021}
$$

which had an nverage percent doviation. of 10.48 . The percont deviatlon ac a point. wne deffned an the quantity of the sboolste difference betwien the data value and tae equation ralue, divided by the data ralue. The average percent deviation is the sum of the individual deviations divided by the number of data points. The best currelation for all of the constant heat oux data was

$$
N u_{B}=0.221 R a_{\partial}^{0.200}\left(L / R_{1}\right)^{0.104} \operatorname{Pr}^{0.010} \text {, }
$$

which had $\mathrm{sa}$ average percent deviation of 11.03 .

There were two major seometric efícels :vident in the experimental data. First, a olaggried cylinder arrangement bad a bigher average beat transfer coefficical than an in-line arrangement of comparable size aut opaciog. Second, and more pronounced, was the increase in the average heal transfer coefficicat when the opacing betwcen cylinders increased and the lotal surfacc arca of the cylinder array decreased. When the results of this study were combined with those of Crupper [5], it became apparrat that an increase in the cylinder apacing led to a relative increase in the local beat transter cocficients of the upper cylinder rows.

The seometric eflect of changing the cylinder spacing and tolal surface area became less pronounced with an increase in the Prandil number of the fluid medium. However, the Prandtl number of the fluid did not influence the effect of changing from an in-line sriay to a staggered array of comparable size and spacing. The beot correlations for the nir, water, 20 cs oilicone, and $06 \%$ alycerine wire:

$$
\begin{aligned}
& N u_{u}=0.0097 R a_{0}^{0.207}\left(L / R_{1}\right)^{0.820} \mathrm{Pr}^{-11.171} \text {, }
\end{aligned}
$$

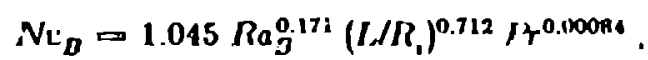

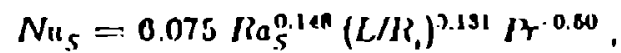

and

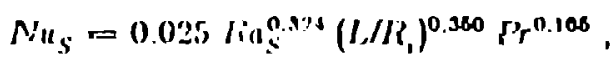

with average perecul deviationu of $11.26,5.51$. 3.08, and 1.04, resnictively

All of the experimental data from this inves. cigation are shown graphically in Figure 4, along with lhe data of Ciupece (6) for four herizontal in-line cyliadern. As uhown in Figure f, there is very littic difference between the correlationn for tne in-line and the stmggered arrangementa. The beat correlation for the combined dats of the inliue arraugeincalo ivno 


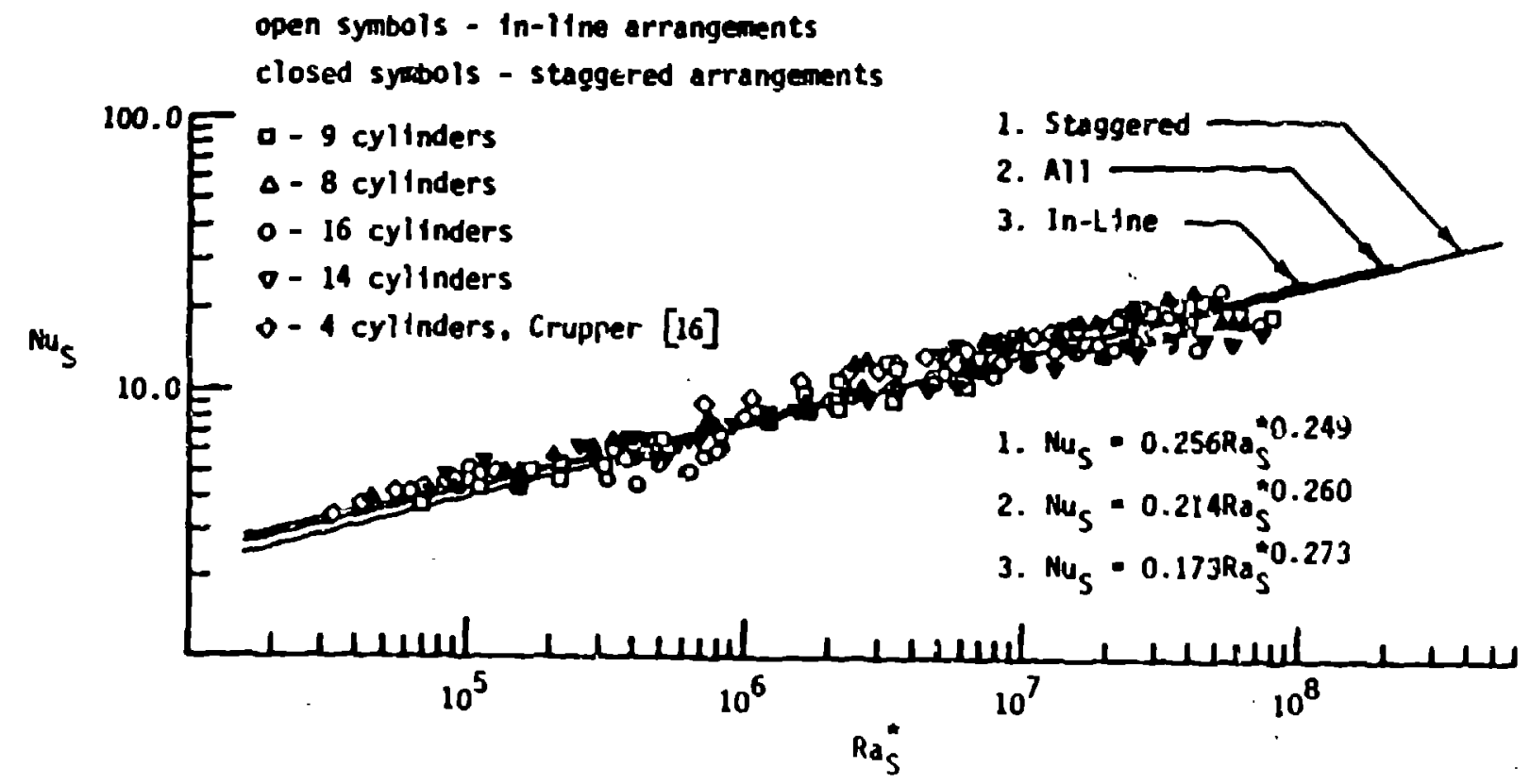

Figure 4. Heal transfer correlations for the in-line data, the staggered data, and all of the data combined

$$
N_{u_{s}}=0.174 R a_{s}^{0.200}\left(L / R_{s}\right)^{0.281} P^{0.017}
$$

witl in arcrage percert deviation of 10.30 . The besc correlation for the combied dala of the uiaggered arrangements was

$$
N_{u_{s}}=0.217 R_{s}^{0.2210}\left(L . / i P_{1}\right)^{0.200} R^{0.020}
$$

with an averse pescant deriation of 10.70. The beat correlatione for all of the experimental data, bryed on onc, two, or three corrclating paraneters were:

$$
\begin{aligned}
& N_{1{ }^{3}}=0.2140 \mathrm{Ra}_{s}^{0.200} \text {. } \\
& N_{u_{s}}=0.213 R n_{s}^{0.201}\left(I . / R_{1}\right)^{0.20 s} \text {, } \\
& \text { ind }
\end{aligned}
$$

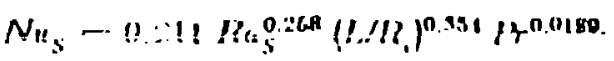

where

$$
\begin{aligned}
& 0.020<\left(I . / R_{1}\right) \leq 1.011 \\
& 0.305 \leq 1+\leq 1.300 \times 104
\end{aligned}
$$

$$
\begin{aligned}
& 4.140 \times 10^{4} \leq R a_{s} \leq 1.170 \times 10^{8} \\
& 4.633 \times 10^{4} \leq R a_{s} \leq 8.153 \times 10^{7}
\end{aligned}
$$

and they had average percent deviations of 12.00 , 11.86 , and 10.71, respectively.

\section{CONCLUSIONS}

This investination has addecl to the amount of avnilablo da:a for heat transter betwicn multiple bodies and an enclosure. Because there was no apprecialle difference in the average hrat transfer coctheient for isothernial and constant heat flux inner body conditions, the applicability of the correlation resulen was grcally ierceased. llowever. the local heat tranefer cocflle irntil of the unger rown of cylinders, when compared on the bottoin row of cylinders, were much higher for conatant heat thux inner body conditiona than tisey were for isothormal inner body conditions. The conatart heat flux condition foreed the upper rows to a higher temperature and augmented the drying gotential for beat tranafor, which resulted in itgher boeal hent cranifer coellicienta for the 
apper rows.

Tho dianance between cylinders and the anount of inner body ourface area were the dominale sactors infuenciag the average heat tranofer coeficient. Av increase in the Prandtl number of the Avid medium dampened the effects of spacing and surfact area whereas the enclosure dampened the efecta changing from an in-line to a staggerad arrangement.

\section{REFERENCES}

1. Wartinglon, R. O., Natura! Convection Heat Tranafer Between Bodies and Their Eaclosure," Ph.D. Disseration, Montana State Usiversity, 1075.

2. Larnon, David W., Gartlirg, David K., and Schimmel, Waluer P., "Natural Convection Studieo in Nuclear Spent-Fuel Shipping Casks: Computation and Experiment," Journal of Energy. Vol. 2, No. 3, 1073.

3. Dutlon, J. C. and tyelty, J R., "An Experimental Study of Low Prandtl Number Natural Coovection in an Array of Uniformly Healed Vertical Cyliuderu," ASME, Heal Transfer Division, Paper No. 75-HT-AAA, Feb. 1075.

1. Van De Sande, E. and Haner, P. J. G., "sleady und Trausient Natural Convection in Enclosures Belween Horizuntal Circular Cylinders (Conutane Heat Flux)," International Journal of Heat and Mass Transfer, Vol 22, ng. 361-370, 1070.

6. Crupper, Gordon, "Nulural Conxaction Heat Transter Between a Fixed Array of Cylioders and its Cubical Enclu: ure," M.S. Thesis, Montana Stalo University, 1077.

0. Powe, R. E., Bounding Efferts on the Heat Lons by Frce Convection Froun Spheres and Cylinders," I'ransactions $\Lambda$ SivE, Journal of Ileat Transfer, Vol. Mo. Ser. C, No. 1, pp. 558-500), Nov. 1074.

7. Brown, P. K., "Nalural Convection Iteal Transter Within Enclosures al Reduced Pressuren," M.S. Thenis, Montana Stale University, 1080.

8. Powo, R. E., Warrington, R. O., and Scanlan. J. A. "Natural Convection Flow Retweeu a Body and its Spherical Encloouro," International Jouraal of lleat and Mase Transfer, Vol. 23, pp. $1337-1350,1080$. 